A. J. DARK AND S. N. RIZK: PROGRESSIVE FOCAL SCLEROSIS OF RETINAL ARTERIES

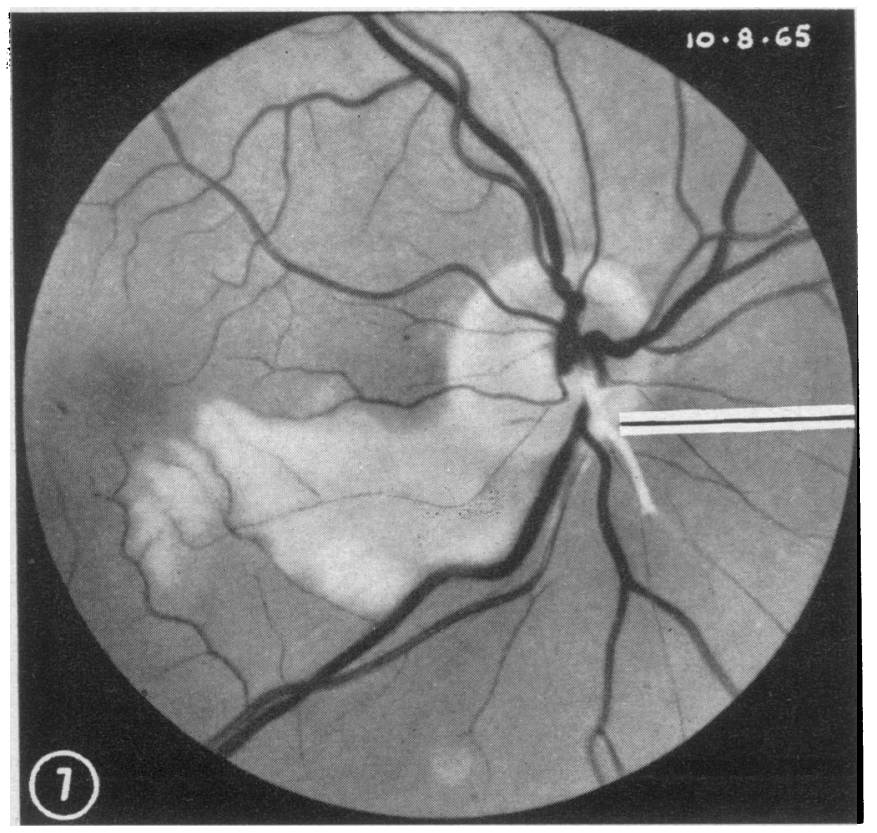

FIG. 7.- $a$ " has been occluded with subsequent extensive infarction of the retina. ( $\times 10$.

OTTO LJUNGBERG ET $A L .:$ MEDULLARY THYROID CARCINOMA AND PHAEOCHROMOCYTOMA

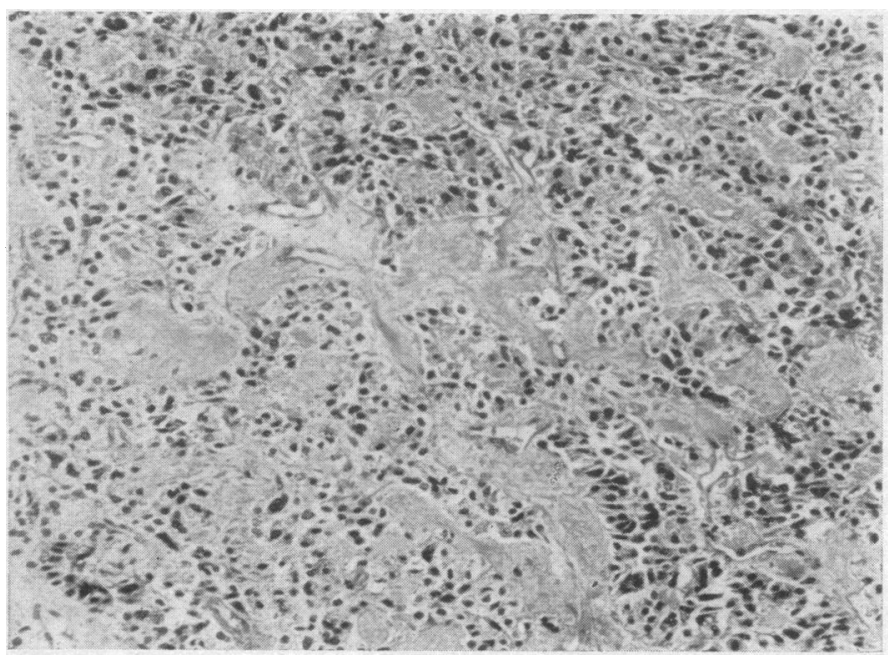

FIG. 1

Fig. 1.-Classical picture of medullary thyroid carcinoma (Case 7) with small irregular clusters of tumour cells in the stroma and a varying amount of amyloid. (Haematoxylin-erythrosin. $\times 125$. .)

Fig. 2.-Carcinoid-like picture of medullary thyroid carcinoma (Case 7) with large and small nests of small tumour cells poor in cytoplasm with a tendency to palisade arrangement of the cells in the margin. The stroma is sparse and the deposition of amyloid scanty. (van Gieson. $\times 78$.)

FIG. 3.-Spindle-cell picture of medullary thyroid carcinoma (Case 12) with elongated regular tumour cells crowded in whorls and streaks and with marked tendency to palisade formation: The stroma here is scanty and the deposition of amyloid insignificant. (Haematoxylin-erythrosin. $\times 100$.)

FIG. 4.-Section from right-sided phaeochromocytoma (Case 10). The picture agrees with that of a phaeochromocytoma with small alveolar formations of polygonal cells rich in cytoplasm in a delicate connectivetissue stroma. Specific green-staining of the cytoplasm in most of the cells. (Potassium bichromate and Giemsa staining. $\times 100$.)
OTTO LJUNGBERG ET $A L .:$ MEDULLARY THYROID CARCINOMA AND PHAEOCHROMOCYTOMA

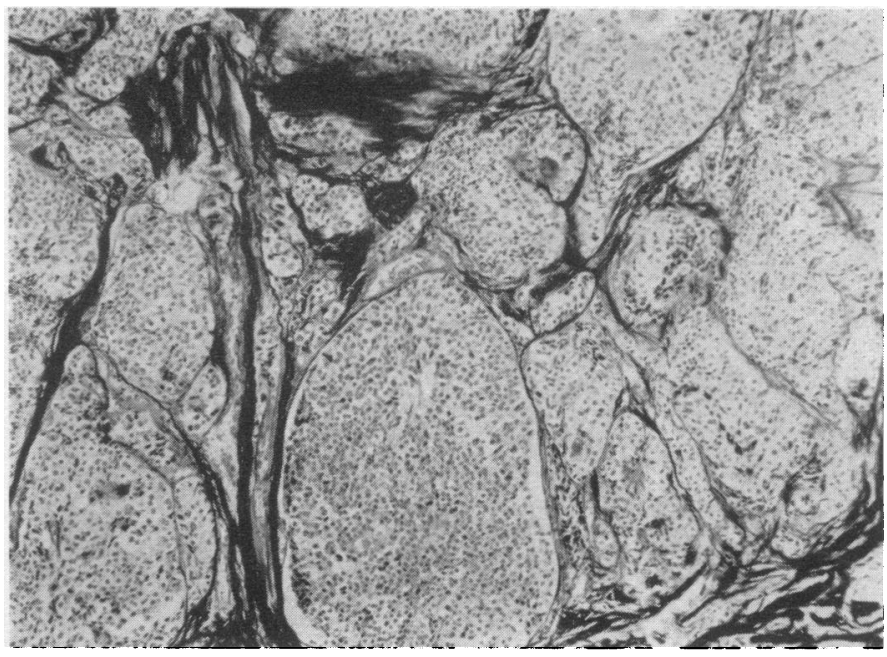

Fig. 2

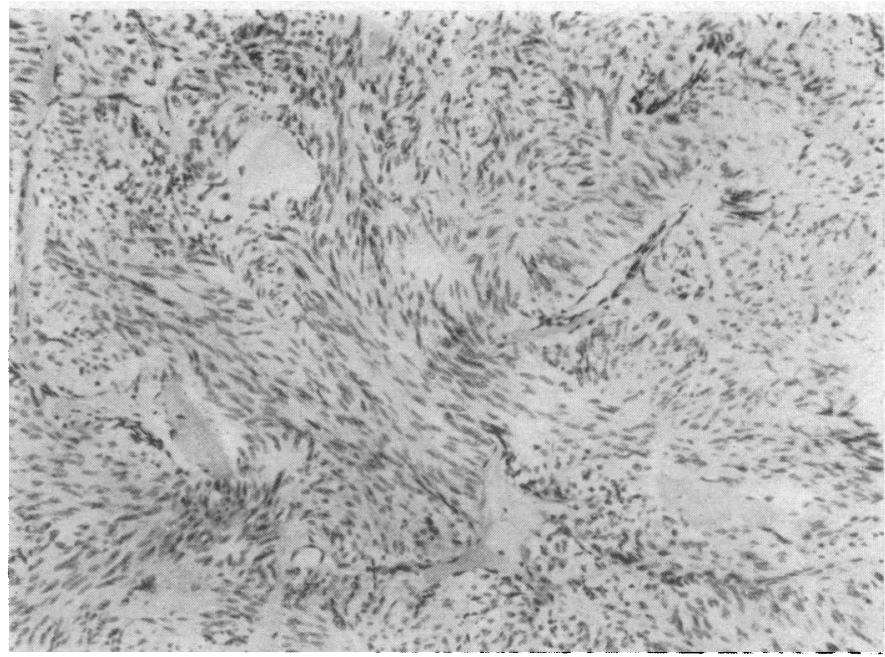

FIG. 3

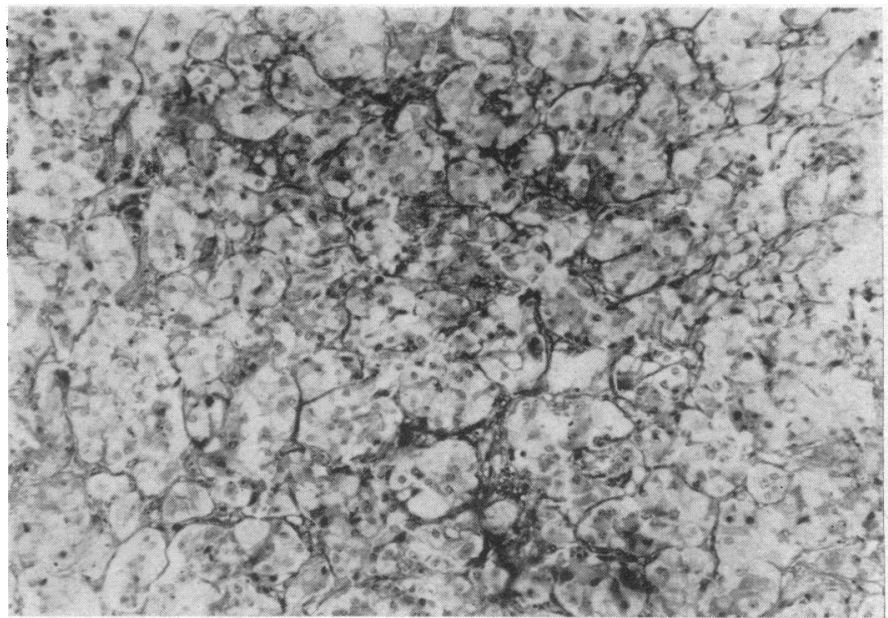

FIG. 4 


\title{
Medullary Thyroid Carcinoma and Phaeochromocytoma: A Familial Chromaffinomatosis*
}

\author{
OTTO LJUNGBERG, $†$ M.D. ; EBBE CEDERQUIST, $\ddagger$ M.D. ; WILFRIED voN STUDNITZ,§ M.D.
}

[With Special Plate]

Brit. med. F., 1967, 1, 279-281

Coexistence of thyroid cancer and phaeochromocytoma was first reported by Eisenberg and Wallerstein in 1932 ; since then some 20 cases have been described (Williams, 1965). In most of these cases the thyroid cancer was of the rare medullary type with amyloid in the stroma (Hazard, Hawk, and Crile, 1959). The familial occurrence of thyroid cancer and phaeochromocytoma has also recently been reported (Nourok, 1964 ; Schimke and Hartmann, 1965; Ljungberg, 1966). We have found this combination in a number of cases and have had the opportunity of examining a family several members of which had both types of tumour associated with multiple cutaneous tumours resembling fibromas; one of them also had café-aulait-like skin spots. The results of this investigation are presented below.

\section{Clinical Material and Methods}

Information regarding 150 members of the family was collected by personal interviews, by telephone, and by analysis of the hospital records and necropsy reports. A special inquiry was made for symptoms of goitre, functional disorders of the thyroid, arterial hypertension, and other cardiovascular signs of phaeochromocytoma, carcinoid syndrome (flushing, pulmonary or gastrointestinal disorders), signs of hyperparathyroidism (nephrolithiasis), skin tumours, and/or café-au-lait skin spots. So far seven patients with definite symptoms or signs have been examined clinically.

\section{Results}

\section{Clinical Picture}

Relevant anamnestic data are given in Table I. The first sign of the thyroid disease was, as a rule, a slowly progressive, fairly firm, uninodular, or multinodular enlargement of the gland. In Case 3 the disease started with hardening and enlargement of a supraclavicular lymph node. The changes progressed slowly and sometimes remained stationary for long periods. In Cases 7, 8, and 10 the onset of goitre was accompanied by temporary dryness and brittleness and loss of head hair, but not by any more specific symptoms or signs of hypothyroidism.

Seven of the patients (Cases 1, 2, 3, 7, 10,11, and 12) had or had had acute attacks of cardiovascular disease, starting with bradycardia, paraesthesia and pallor of the face, hands, and feet, severe pounding headache, and dyspnoea, followed by tachycardia, a sensation of heat, and reddening of the peripheral parts of the body, and, in some cases, also a tendency to perspiration. * Supported by grants from the Medical Faculty of the University of

t Junior Lecturer, University Department of Pathology, General Hospital, Malmö, Sweden.

‡ Assistant Professor, Department of Radiotherapy, University Hospital, Lund, Sweden.

$\checkmark$ Assistant Professor, University Department of Clinical Chemistry, General Hospital, Malmö, Sweden.
This cardiovascular complex (Table I) showed a remarkably constant pattern in all these seven patients, though the severity and frequency of such attacks varied. They were often precipitated by physical exertion or psychical stress, but several of these patients reported that the symptoms had been caused by mechanical pressure against the left or right flank. The woman (Case 3) who died at the age of 76 from metastases from a

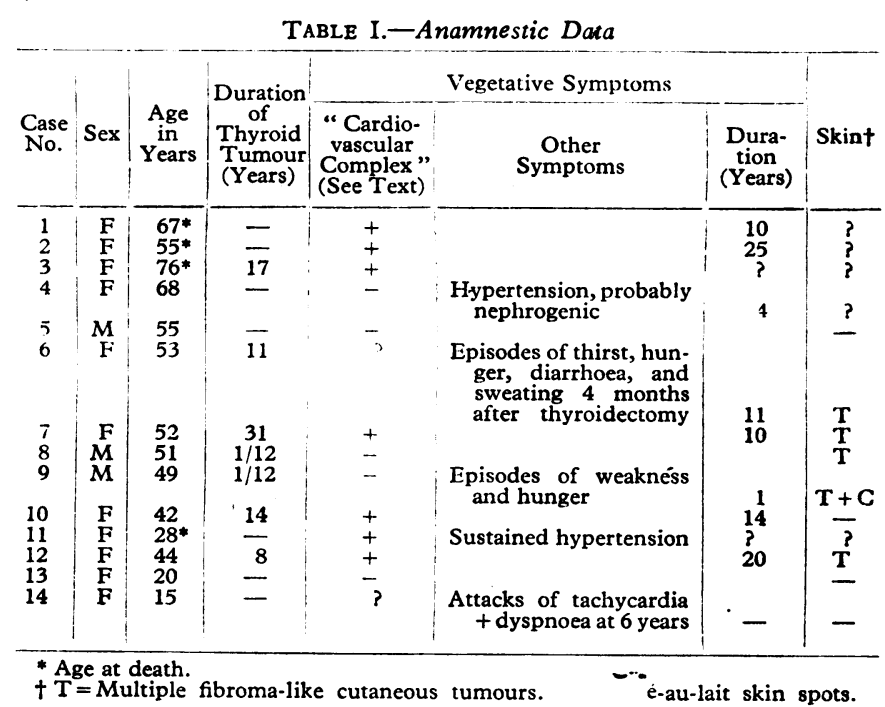

medullary thyroid cancer had had increasingly severe cardiovascular episodes concomitant with the progress of the thyroid disease during the last few months of her life.

In only two cases (Nos. 4 and 11) did hypertension occur.

Five patients (Cases 6, 7, 8, 9, and 12) had multiple fibromalike cutaneous tumours up to 1 by $1 \mathrm{~cm}$. in size, mostly situated on the face and limbs. One patient (Case 9) also had multiple café-au-lait-like skin spots, up to $7-8 \mathrm{~cm}$. in diameter, on the trunk, and a few also on the limbs. Another patient (Case 6) had nephrolithiasis in her history.

\section{Heredity}

The family tree shows the central part of the pedigree. Only individuals included in this part were investigated. The syndrome was most common in two groups of sibs, their mothers, and their maternal grandmother. Medullary thyroid carcinoma was proved in seven of these members (Cases 3, 6, 7, 8, 9, 10, and 12). The cardiovascular complex was found in seven (Cases $1,2,3,7,10,11$, and 12) and possibly also in one (Caso 14) of the children of Case 7.

The syndrome, whether complete or partial, was much more common among females (10 females and 2 males; one female and one male lacked clear symptoms). Neither of the males had cardiovascular symptoms. 


\section{Clinical and Laboratory Studies}

The most important clinical and laboratory data are given in Table II. Thyroid function appeared to be normal (basal metabolic rate, protein-bound iodine, T3-uptake test, ${ }^{13}{ }^{1} \mathrm{I}$ turnover, serum cholesterol). The scintiscan showed no uptake of radioiodine within the thyroid tumours. Autoantibodies against thyroid tissue could not be demonstrated. Parathyroid function also appeared to be normal (skeletal $x$-ray, serum calcium, serum phosphorus, serum alkaline phosphatase).

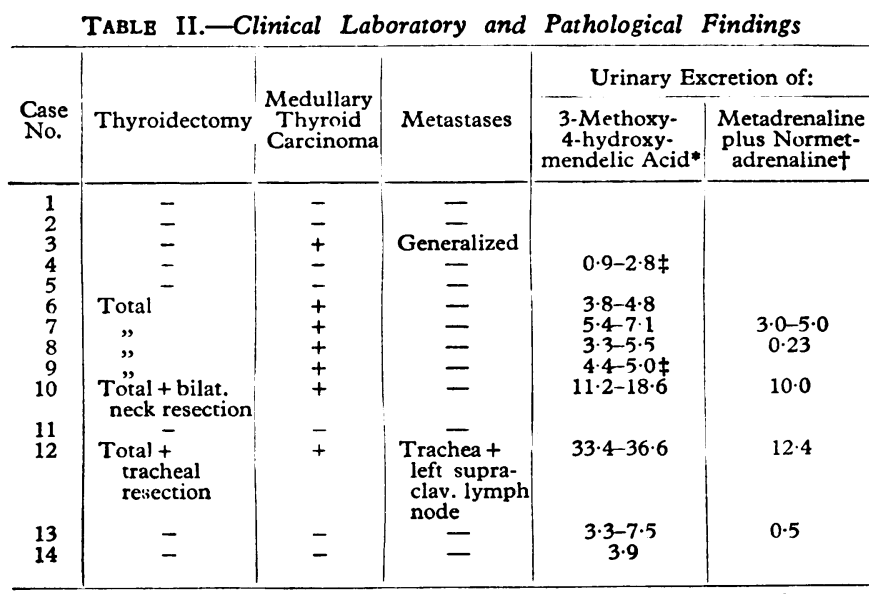

* According to Pisano et al. (1962). Normal range: 3.2-6.6 mg./24 hours, or 2.0-7.2 mg./g. creatinine.

$\ddagger$ These values are given in mg./g. creatinine; all the others are in mg./24 hours.

In four patients (Cases $7,10,12$, and 13) the urinary excretion of monoamines with metabolites was significantly increased. The lowest and highest values found for urinary 3-methoxy-4hydroxy-mandelic acid and combined metadrenaline and normetadrenaline are given in Table II, from which it is clear that the values found for one or the other of these compounds were abnormal in all four patients. Separation of metadrenaline and normetadrenaline showed that in Cases 7, 10, and 12 at least half of the combined metadrenaline and normetadrenaline consisted of metadrenaline. The tyramine test for phaeochromocytoma (according to Engelman and Sjoerdsma, 1964) was done in seven cases (Nos. 5, 6, 7, 8, 9, 10, and 12) and was negative in all. These findings, analysed in further detail, are to be described elsewhere (von Studnitz and Ljungberg, 1966).

The urinary 5-hydroxy-indole-acetic acid was determined (according to Hanson and Serin, 1955) in nine patients (Cases 5 to 14 ) and was invariably normal.

Selective angiography done in Cases $4 ; 6,7,8,9,10$, and 12 revealed a fist-sized suprarenal tumour on the right side in Cases 7 and 10 and on the left side in Case 12.

\section{Pathology}

Thyroid tumours were diagnosed in seven of the cases studied. The extent of the tumours and the operations performed are given in Table II.

The extirpated tumours consisted of multiple, usually circumscribed, sometimes encapsulated, foci with slightly bulging pale-brown cut surfaces. Case 12 also had two rounded colloid adenomas of about 1.5 by $1.5 \mathrm{~cm}$. The histological picture varied not only from one to another of the seven tumours but also within one and the same tumour.

Some sections showed the characteristics described by Hazard et al. (1959)-namely, irregular clusters of tumour cells with moderate or slight cellular polymorphism, regular cellular nuclei, and a low frequency of mitotic figures in a stroma with a varying amount of amyloid substance (Special Plate, Fig. 1).

In other areas, also in one and the same thyroid gland, there was a variant resembling a carcinoid tumour with cell nests varying in size and built up of small cells poor in cytoplasm and with the marginal cells arranged in palisade-like fashion. The stroma in these parts was scanty, and amyloid was insignificant or absent (Special Plate, Fig. 2).

In other areas a spindle-cell tumour was seen with elongated regular cells arranged in whorls and streaks and with an obvious tendency to palisade arrangement. The stroma in these areas was very scanty and there was little or no deposition of amyloid (Special Plate, Fig. 3).

The right-sided suprarenal tumour extirpated in Case 10 consisted macroscopically of an oval, soft, encapsulated tumour, 6.5 by 4 by $4 \mathrm{~cm}$. The upper pole showed a narrow rim of yellow adrenocortical tissue. Histologically, the picture was that of a phaeochromocytoma. The tumour differed morphologically from the medullary thyroid tumours and contained no amyloid (Special Plate, Fig. 4).

So far no representative skin tumour has been examined histologically.

\section{Discussion}

Sipple (1961) was one of the first to suggest that the combination of thyroid cancer and phaeochromocytoma might be a clinical entity. Since then various observations favouring this opinion have been published-for example, the common occurrence of the medullary type of thyroid carcinoma, the usually bilateral occurrence of phaeochromocytoma, the finding of other neuro-ectodermal tumours in these patients, and, finally, the frequently familial character of the disease. Medullary thyroid carcinoma tends to appear in the form of multiple foci 
in one and the same gland. Though these foci may represent intraglandular metastases, they are more likely to be a multifocal manifestation of the disease. Recent investigations (Hazard et al., 1959; Woolner et al., 1961 ; Freeman and Lindsay, 1965 ; Williams et al., 1966) suggest that in this type of thyroid carcinoma the clinical course may fluctuate considerably. Thus in our Case 7 the goitre had existed for at least 30 years without signs of invasion. On the other hand, in Case 12 it had existed for about eight years when operation revealed signs of involvement of the trachea and of metastasis to the regional lymph nodes. This type of carcinoma can obviously occur in childhood (Ljungberg, 1966), but it is usually not diagnosed before the age of 30 . In published series the disease is more common among females, the ratio being $3: 2$.

In at least two-thirds of the 20 or so cases of coexisting thyroid carcinoma and phaeochromocytoma on record the thyroid carcinoma was of the medullary type. Not all of the cases were reviewed; the true figure was therefore surely higher, and it is probable that the medullary type is specifically correlated with the familial form of thyroid carcinoma and phaeochromocytoma (Williams, 1965 ; Schimke and Hartmann, 1965 ; Ljungberg, 1966).

Phaeochromocytoma was bilateral in about $70 \%$ of all cases on record. Some of the patients also showed signs of multiple neurofibromatosis (von Recklinghausen's disease). It is interesting to note that in some published cases phaeochromocytoma recurred at the same site after operation or appeared in the corresponding contralateral region. Phaeochromocytoma has also been reported in an accessory adrenal gland (Ljungberg, 1966). These observations, together with the multifocal character of the medullary thyroid carcinoma, may indicate a multifocal change, induced by some superior, governing principle.

In recent reports of the familial occurrence of the syndrome it is contended that the disease should be regarded as a distinct genetic entity with an autosomal dominant mode of inheritance (Schimke and Hartmann, 1965). The distribution of the cases in the family under discussion is compatible with such a view. A sex-linked heredity appears improbable, since Cushman (1962) has described a family in which transmission was from father to son. The possibility of autosomal recessive heredity with consanguineous marriages in the family must of course also be considered-though no such marriages could be traced in the family described here.

Several possible explanations of the pathogenesis of the disease may be considered. For example, the syndrome may be a manifestation of a genetic pleiotropism, as may be the case in multiple endocrine adenomas. Thyroid carcinoma and phaeochromocytoma have occasionally been associated with hyperplasia or adenoma of the parathyroid glands. Wermer (1963) gave a thorough description of the pluriglandular syndrome and showed that it is the hypophysis, the island cells of the pancreas, and the parathyroid glands that are affected. However, until more cases of coexisting multiple endocrine adenomas and thyroid carcinoma with phaeochromocytoma have been reported this question must remain open.

The occurrence of other multiple neural tumours, the common occurrence of bilateral phaeochromocytomas, and the fact that phaeochromocytoma has been found in an accessory adrenal in patients with this syndrome more likely suggest the existence of a genetically determined systemic disorder of a single cellular system, probably the chromaffin-cell system-that is, a familial chromaffinomatosis. Recent investigations (Ljungberg, 1966) support this view. In sections from four medullary thyroid carcinomas (Cases 6, 7, 9, and 12) treated with potassium bichromate or potassium iodate we have observed clusters of neoplastic cells with green or brown cytoplasmic granules of the type seen in chromaffin tissue. Also, sections treated with silver salts (according to Masson-Hamperl, described by Romeis, 1948) have shown argentaffin tumour cells. Three medullary thyroid carcinomas (Cases 6, 7, and 12) were studied with a sensitive and specific fluorescent microscope technique for demonstrating certain monoamines (Falck et al., 1962 ; Falck, 1962). This technique showed clusters of cells with tluorescerice specific of monoamines, and such fluorescence was also seen in the phaeochromocytoma extirpated in Case 10 (Ljungberg and Falck, to be published). Spectrophotometric analysis (by methods described by Bertler, Carlsson, Rosengren, and Waldeck, 1958, and Bertler and Rosengren, 1959) showed 5-hydroxytryptamine in all the medullary thyroid carcinomas examined and in the phaeochromocytoma from the patient in Case 10 (Ljungberg and Rosengren, to be published).

According to Williams (1966), medullary thyroid carcinoma may perhaps arise from the parafollicular or interstitial cells demonstrated in certain mammals and shown to contain 5hydroxytryptamine (Falck et al., 1964) in sheep. These cells have, however, not been demonstrated in human thyroid tissue. Nothing definite can be said in this respect about the genesis of the presence of the syndrome " medullary thyroid carcinoma and phaeochromocytoma" until we are in possession of more reliable information-that is, until it has been unequivocally decided whether or not parafollicular cells occur in man.

\section{Summary}

A preliminary account is given of a family in which cases of medullary thyroid cancer and phaeochromocytoma occurred in association with multiple fibroma-like cutaneous tumours, and in one case with café-au-lait skin spots. Information about 150 members of the family was collected. Seven were found to have medullary thyroid carcinoma. Eight had or had had symptoms suggestive of phaeochromocytoma, and in four of them the urinary catecholamines were increased. In three patients suprarenal tumours were verified radiographically and a right-sided phaeochromocytoma had recently been removed from one of them.

Preliminary results suggest that the syndrome " medullary thyroid carcinoma and phaeochromocytoma" is an inherited disorder of the chromaffin system and should therefore be regarded as a familial chromaffinomatosis.

Addendum.-Adrenalectomy has since been performed in Cases 7 and 12 and revealed unilateral phaeochromocytomas (weighing $27 \mathrm{~g}$. in Case 7 and 1,020 g. in Case 12), verified by histological examination. The results of histochemical and chemical examination in Case 12 are in accordance with the previous findings in Case 10.

\section{REFERENCES}

Bertler, A., Carlsson, A., Rosengren, E., and Waldeck, B. (1958). $K$. fysiogr. Sällsk. Lund. Förh., 28, 121.

and Rosengren, E. (1959). Experientia (Basel), 15, 382.

Cushman, P., jun. (1962). Amer. F. Med., 32, 352.

Eisenberg, A. A., and Wallerstein, H. (1932). Arch. Path., 14, 818.

Engelman, K., and Sjoerdsma, A. (1964). F. Amer. med. Ass., 189, 81. Falck, B. (1962). Acta physiol. scand., 56, Suppl. No. 197.

Hillarp, N-A., Thieme, G., and Torp, A. (1962). $f$. Histochem.

Cytochem., 10, 348 .

Larson, B., von Mecklenburg, C., Rosengren, E., and Svenaeus, K. (1964). Acta physiol. scand., 62, 491.

Freeman, D., and Lindsay, S. (1965). Arch. Path., 80, 575.

Hanson, A., and Serin, F. (1955). Lancet, 2, 1359.

Hazard, J. B., Hawk, W. A., and Crile, G. (1959). F. clin. Endocr., 19, 152 .

Ljungberg, O. (1966). Opusc. med. (Stockh.), 2, 57.

- and Rosengren, E. (1967). Submitted for publication.

Nourok, D. S. (1964). Ann. intern. Med., 60, 1028.

Pisano, J. J. (1960). Clin. chim. Acta, 5. 406.

Pisano, J. J. (1960). Clin. chim. Acta, 5. 406.

Romeis, B. (1948). Mikroskopische Technik, 15id., 7, 285.

Schimke, R. N., and Hartmann, W. H. (1965). Ann. intern. Med., 63. 1027

Sipple, J. H. (1961). Amer. F. Med., 31, 163.

Studnitz, W. von, and Ljungberg, O. (1967). Submitted for publication Wermer, P. (1963). Amer. F. Med., 35, 205.

Williams, E. D. (1965). ₹. clin. Path., 18, 288. (1966). Ibid., 19, 114

Brown, C. L., and Doniach, I. (1966). Ibid., 19, 103.

Woolner, L. B., Beahrs, O. H., Black, B. M., McConahey, W. M., and Keating, F. R., jun. (1961). Amer. f. Surg., 102, 354. 